\title{
CHEMICAL IDENTIFICATION OF SEMI-URBAN AEROSOLS BY LASER RAMAN SPECTROSCOPY
}

\author{
V.M. HARPALE ${ }^{1, *}$ \\ S.D. RALEGANKAR ${ }^{1}$ \\ S.D. DHOLE ${ }^{2}$ \\ D.B.JADHAV ${ }^{3}$
}

Received: 14/11/05

Accepted: 02/05/06

\author{
${ }^{1}$ Department of Physics, Ahmednagar College \\ Ahmednagar (M.S.), India \\ ${ }^{2}$ Department of Physics, Pune University, Pune, India \\ ${ }^{3}$ Indian Institute of Tropical Meteorology, Pune, India
}

*to whom all correspondence should be addressed: e-mail:vmharpale@yahoo.com

\begin{abstract}
Atmospheric aerosols play an important role in local, regional meteorology, visibility, air pollution, haze formation and energy balance of radiation. These processes influence the climate directly or indirectly. Therefore, for increasing importance of aerosols in understanding the various environmental processes and public health; it is necessary to have accurate physical and chemical identification of these aerosols. The Raman scattering has only recently been demonstrated as potential analytical method for chemical identification of aerosol particles [1], [2]. This technique is used for the chemical identification of aerosol at Ahmednagar (INDIA). Various spectroscopic techniques have been applied for the identification of the matter, while most of these techniques can be adopted as a routine analytical procedures for bulk samples. They may not be practical for aerosol samples at all. Each of these techniques has its advantages and disadvantages. For in situ identification of aerosol particles, however, Raman scattering is currently the most promising technique. It has small scattering cross-section but large number of advantages. We have explored the use of Raman Spectroscopy for the identification of aerosol particles of urban, rural, and industrial areas. The aerosol samples are collected on pure quartz filters with high volume aerosol sampler and Raman spectra is obtained using Raman spectrometer. It uses double monochromator with diffraction grating having 1800 grooves $/ \mathrm{mm}$ and diode laser $(532 \mathrm{~nm}$ wavelength) with $25 \mathrm{~mW}$ Power. The spectra of aerosol samples are collected in the perpendicular direction to the incident laser beam from the surface of filter containing aerosols. Thus, the various aerosol samples have been investigated for their chemical speciation. The Raman spectra for atmospheric aerosols appears in the region $607 \mathrm{~cm}^{-1}$ to $937 \mathrm{~cm}^{-1}$. The peaks at $607 \mathrm{~cm}^{-1}$ and $647 \mathrm{~cm}^{-1}$ [3] correspond to Ammonium sulphate and Ammonium bicarbonates present in environmental aerosols respectively. In addition to this the Raman shifts at $847 \mathrm{~cm}^{-1}$ and $937 \mathrm{~cm}^{-1}$ are equivalent to potassium bisulphate and potassium chlorate. These are the major chemical species present in the semi-urban environment of Ahmednagar city. This region is dominated by low rainfall; dry weather and having relative humidity around $40 \%$. The region is surrounded by the agriculture land producing sugarcane as a major agriculture crop. Hence, the aerosol chemical identification of this region would be an additional contribution to the data on aerosols.
\end{abstract}

KEYWORDS: Particulate matter, environment, humidity, low rainfall, chemical species, sampling, Raman spectra, quartz filters, monochromator, organic and inorganic compounds, grating, air sampler, chemical composition, groove density, air pollution. 


\section{INTRODUCTION}

The aerosol particles play an important role in many branches of science such as environmental pollution, atmospheric chemistry public health and meteorology. These particles are not dangerous simply because they are small but rather because of the material present within them, which they carry into the lungs. In atmospheric sciences, the chemical identification of individual aerosol particles, their size distribution and chemical composition is of great relevance for the modelling of atmospheric and environment processes [4], [5]. Detail knowledge of chemical composition is vital for understanding the kinetics of heterogeneous chemical reaction of particles and the gas molecules surrounding it. The need for the chemical identification of particles become even more obvious when considering the fact that, such heterogeneous processes are occurring in everyday life and also involved in many energy conversion systems, manufacturing processes and health related areas as well. In order to make better assessment of the origin and the environmental effects of airborne particles, it is important to explore new techniques for their chemical identification. The chemical identification includes the identification of the gas phase as well as particulates matter. The pioneering papers [6], [7], [8], [9], on chemical identification have been published on graphite particulates. Many spectroscopic techniques have been applied to aerosol particles while most of these techniques can be adopted as routine analytical procedures for bulk samples, they may not be practical for aerosol samples at all. Each of these techniques has its advantages and disadvantages. Raman scattering, has only recently been demonstrated to be a potential analytical method for chemical identification of aerosol particles [10]. It has small scattering cross section but large number of advantages as follows [11]:

i. It can provide high sensitivity with comparable selectivity and chemical speciation.

ii. In addition to this, it is usually capable of covering lower wave numbers than infrared spectrometer extending down to $100 \mathrm{~cm}^{-1}$ where as most infrared stops at $200 \mathrm{~cm}^{-1}$

iii. In many cases, sample preparation is often simpler for Raman spectroscopy than in case of infrared.

iv. It is usually useful for any state of matter like gas, solid and liquid. Using this technique, any type of inorganic, organic and biochemical species in the form of liquid, gas or solid can be identified.

The basic theory and applications of Raman scattering applied to aerosol particles have been recently reviewed [10]. This technique is used for the chemical identification of aerosols at Ahmednagar (India).

\section{EXPERIMENTAL SET- UP}

Raman spectroscopy is an ideal tool for the investigation of chemical composition [9] of aerosol, since their spectra have found to respond the changes in microstructure of aerosol. In this paper we describe the application of new and highly specific analytical technique, Raman spectroscopy, for the chemical identification of aerosol particles. This technique is unique in the sense that, the Raman spectra are determined by the amount and the chemical species present in the particle. This information is complementary to that obtained by study of gas chromatography and infrared spectroscopy.

\subsection{The Principle of Raman Spectromter}

Raman effect provides the basis for Raman spectroscopy and has been extensively described [12], [13], [14]. When a monochromatic beam of visible light, usually from a laser source, is focused on sample (which may be solid, liquid or gas), it gets scattered. When the scattered light is examined with a spectrometer, a series of emission lines will be observed. The strongest line appears at the frequency of the exciting monochromatic light source and is due to Rayleigh scattering. Symmetrically placed on the either side of the Rayleigh line are a number of very much weaker lines, these being the Raman emissions. The Raman emissions on the low frequency side of the Rayleigh line are called stokes line and are of higher intensity than the anti stokes lines, which lie on the high frequency side. If the light excites the molecule to a higher vibrational state, it will loose energy and appear with lower frequency. Conversely, if it brings about downward transition it will gain energy and appear at higher 
frequency. The displacement $(\Delta v)$ of these lines (spectra) from Ralyeigh line measured in wave number $\left(\mathrm{cm}^{-1}\right)$ are found to correspond to the frequencies of the molecular vibrations. Thus, these spectra of Raman scattered light, identify the scattering molecule. In case of solid samples, it contains additional information on the molecular order of the solid phase from which the nature and extent of crystallinity may be inferred. The vibrational frequencies, in turn, are related to the masses of vibrating atoms, the bond forces uniting them and their geometrical arrangements.

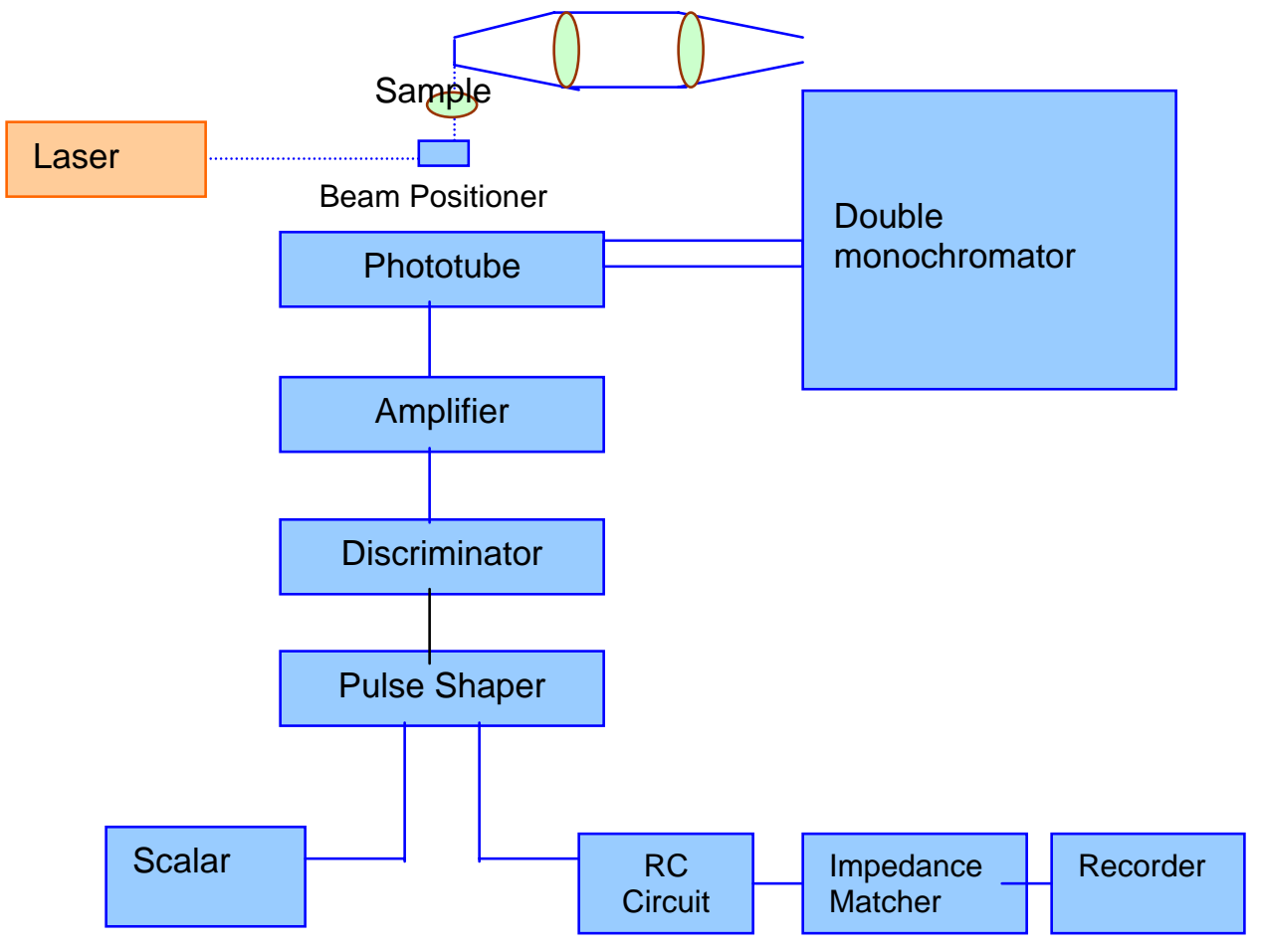

Figure 1. Block diagram of Raman spectrometer.

\subsection{Raman Spectrometer}

We have undertaken to explore the use of Raman spectroscopy for the identification of Atmospheric aerosol particles. For this purpose, we have constructed a Raman spectrometer, rather than purchasing a commercial instrument, because of the extra flexibility this approach affords. The Raman spectrometer used in this experiment is shown in the figure 1 . The instrument consists of: (a) an excitation source (diode laser with $532 \mathrm{~nm}$ wavelength and $25 \mathrm{~mW}$ power) (b) sample cell (c) monochromator (d) detecting system (Photomultipler tube with S-20 response) (e) data acquisition system and computer. The aerosol samples are collected on pure quartz filters with high volume aerosol sampler and Raman spectra is obtained using above experimental set-up. The spectrometer uses double monochromator with diffraction grating having grooves density 1800 grooves $\mathrm{mm}^{-1}$ and diode laser $(532 \mathrm{~nm}$ wavelength) with $25 \mathrm{~mW}$ power. The spectra of aerosol samples are collected in the perpendicular direction to the incident beam from the surface of quartz filter containing aerosols. Thus, the identification of the aerosol samples is carried out using this spectroscopic technique.

\subsection{Selection of substrate (filters) and Aerosol sampling}

The most conventional method of sampling ambient aerosols involves their collection on filters. Several types of plastic films are commonly used as filter media (e.g. Millipore, Nucleopore, etc.) for the collection of ambient aerosols. The filter materials made with inorganic binders, Teflon, polycarbonate or other polymeric materials, however, give unacceptable levels of background fluorescence and therefore are unaccepted [15]. We have collected the aerosol samples from semi-urban areas. Our site is the Ahmednagar college 
campus, located in semi urban area, which is close to Pune- Aurangabad high way. The samples are collected on the terrace of physics department. The samples of ambient aerosols were obtained in short term (24 hours) collections through the use of standard high volume (2 $\mathrm{m}^{3} \mathrm{~min}^{-1}$.) air sampler employing quartz filters. Before the use for collection, these filters are baked at $300{ }^{\circ} \mathrm{C}$ for alteast 2 hours to reduce the organic levels. Also, these filters will be equilibrated for 24 hours at constant relative humidity between $20 \%$ to $40 \%$ as followed by [16] and at constant temperature $15^{\circ} \mathrm{C}$ to $30^{\circ} \mathrm{C}$. This is achieved by placing a filter paper in desiccators at least for 24 hours before investigation for chemical composition using Raman spectrometer. With this procedure, lowest manipulation of the aerosol samples is expected.

\section{RESULTS AND DISSCUSSION}

Many classes of inorganic and organic compounds and materials can be expected to be major constituents of airborne particulate matter. Different workers have concluded that the principal sulfur and nitrogen species are $\mathrm{SO}_{4}{ }^{2-}, \mathrm{NO}_{3}^{-}$and $\mathrm{NH}_{4}{ }^{+}$and suggested that the most likely combinations of these ions are ammonium nitrate [17] and ammonium sulfate [18]. In addition to these species, nitric and sulfuric acid have been implicated as a major pollutant of the atmosphere. We have presented the Raman spectra of urban aerosols in figure 2 to illustrate the kind of spectroscopic information, which is obtained in the sampling of aerosols. The wavelength shift in Angstrom displayed on horizontal axis and the scattered light intensity on vertical axis. The frequency shift $\left(\Delta v \mathrm{~cm}^{-1}\right)$ in wave number is obtained for stokes lines using exciting Rayleigh line $(532 \mathrm{~nm})$. The necessary wavelength calibrations are obtained using Neon emission lines. This discussion centers on the qualitative interpretation of the spectra of aerosol particles originating from semi-urban environment of Ahmednagar town in INDIA. The Raman bands have been observed in the region $607 \mathrm{~cm}^{-1}$ to $937 \mathrm{~cm}^{-1}$. The qualitative comparison of the spectrum of the particle with reference spectra [3] indicate the presence of various inorganic compounds. There are total five active Raman modes have been observed for this sample. These have been assigned frequencies shifts $607 \mathrm{~cm}^{-1}, 647 \mathrm{~cm}^{-1}$, $707 \mathrm{~cm}^{-1}, 847 \mathrm{~cm}^{-1}$ and $937 \mathrm{~cm}^{-1}$. Out of these the bands at $607 \mathrm{~cm}^{-1}$ and $647 \mathrm{~cm}^{-1}$ are identified as ammonium sulphate and ammonium bicarbonate present in the semi- urban environment respectively. In addition to this; the bands at $847 \mathrm{~cm}^{-1}$ and $937 \mathrm{~cm}^{-1}$ are identified as potassium bisulphate and potassium chlorate. These are the chemical species identified in our aerosol sample.

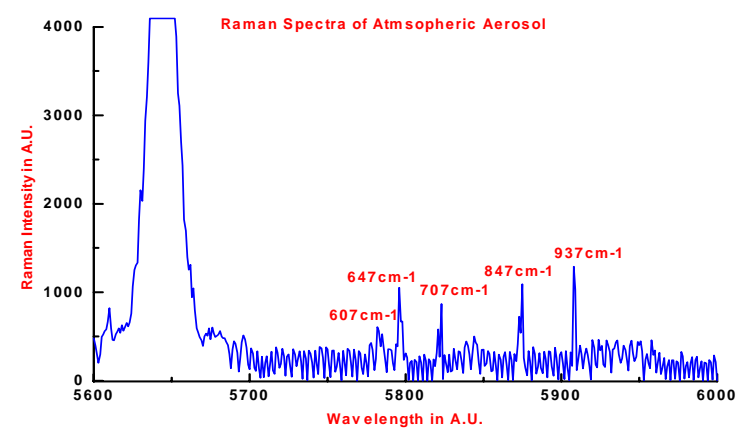

Figure 2. Raman spectra of atmospheric aerosol.

Table 1. Raman frequencies $\left(\mathrm{cm}^{-1}\right)$ and observed chemical species for atmospheric aerosols

\begin{tabular}{ccc}
\hline Sr. No. & Raman frequencies $\left(\mathbf{c m}^{-1}\right)$ & Chemical species \\
\hline 1 & 607 & $\left(\mathrm{NH}_{4}\right)_{2} \mathrm{SO}_{4}$ \\
\hline 2 & 647 & $\mathrm{NH}_{4} \mathrm{HCO}_{3}$ \\
\hline 3 & 707 & $\mathrm{Na}_{2} \mathrm{~S}_{2} \mathrm{O}_{6} .2 \mathrm{H}_{2} \mathrm{O}$ \\
\hline 4 & 847 & $\mathrm{KHSO}_{4}$ \\
\hline 5 & 937 & $\mathrm{KClO}_{3}$ \\
\hline
\end{tabular}




\section{CONCLUSIONS}

Present study has shown that Raman spectroscopy is a powerful tool for qualitative chemical identification of aerosol particles. Ammonium sulphate, ammonium bicarbonate, potassium bisulphate and potassium chlorate present in ambient aerosols as model chemical species have been identified. The molecular nature of the species, its concentration as well as compositional complexity in the aerosol particles are the important variables. These factors and their relationship to single particle analysis are only qualitatively understood. From these observations, we cannot draw any firm conclusions regarding ultimate limits of detection imposed by particle size, the concentration, distribution and the compositional complexity of aerosol particles. We have shown that Raman spectroscopy permits the molecular analysis of a broad variety of environmentally significant materials existing in the form of ambient aerosols. In any program of environmental research, this kind of analytical capability can be expected to yield new answers to the problems that could be partially addressed before.

\section{REFERENCES}

1. Tang I.N. and Fung K.H. (1989) Characterization of Inorganic salts particles by Raman Spectroscopy, J. Aerosol Sci., 20(5), 609-617.

2. Tang I.N. and Fung K.H. (1991) Relative Raman scattering cross-section measurements with suspended particles, Appl. Spectrosc.,45(5), 734-737.

3. Degen I.A. and Newman G.A. (1993) Raman spectra of inorganic ions, Spectrochimica Acta, 49A(5/6), 859-887.

4. Pruppacher H.R. and Klett J.D. (1978) Microphysics of Clouds \& Precipitation, Reidel, Dordrecht.

5. Andreae M.O. (1995) Climatic effects of changing atmosphere, in World survey of climatology, vol 16. Future climates of the world: a modelling perspective, by Henderson Sellers A. (ed.), Elsevier, Amsterdam.

6. Nemanich R.J. and Solin S.A. (1979) First -and Second order Raman scattering from finite size crystals of graphite, Phy. Rev.-B, 20(2), 392-401.

7. Nemanich R.J., Lucovsky G. and Solin S.A. (1977) Optical probes of the lattice dynamics of Graphite, Mater. Sci. Engg., 31, 157-160.

8. Tunistra F. and Koenig J.L. (1970) Raman Spectrum of Graphite, J. Chem. Phys., 53, 1226-1230.

9. Escribano R., Sloan J.J. et al. (2001) Raman spectroscopy of carbon-containing particles, Vibrational spectrosc., 26, 179-186.

10. Schrader Bernhard (1986) Micro-Raman fluorescence \& scattering spectroscopy of single Particles, in Physical and Chemical characterization of individual airborne particles, by K.R. Spurny (ed.), Ellis Horwood, John Wiley, Chichester, New York.

11. Fung K.H., Imre D.G. and Tang I.N. (1994) Detection limits for sulfates and nitrates in aerosol particles by Raman spectroscopy, J. Aerosol. Sci., 25(3), 479-485.

12. Anderson A. (ed.) (1971) The Raman Effect, Marcel Dekker, Inc., New York.

13. Colthup, N.B., Daly L.H. and Wiberley, S.E. (1975) Introduction to Infrared and Raman spectroscopy, $2^{\text {nd }}$ ed., Academic Press, Inc., New York.

14. Hendra, P.J. (1975) Laser Raman Spectroscopy, in Vibrational Spectra \& Structure by Durig J.R. (ed.), Marcel Dekker, Inc., New York.

15. Barthelmie R.J. and Pryor S.C. (1997) Secondary organic aerosols: formation potential and ambient data, Sci. Total Environ., 205, 167-178.

16. Qin Y. and Oduyemi K. (2003) Chemical composition of atmospheric aerosol in Dundee, U.K., Atmos. Environ., 37, 93-104.

17. Gordon R.J. and Bryan R.J. (1973) Ammonium nitrate in airborne particles in Los Angeles, Environ. Sci. Technol., 7, 645-647.

18. Hidy G.M. and Burton C.S. (1975), Int. J. Chem. Kinetics, S1, 509. 